\title{
Competências do enfermeiro na gestão do conhecimento e capital intelectual
}

\author{
Competencies of the nurse in the management of cognitive and capital knowledge \\ Competencias del enfermero en la gerencia del conocimiento intelectual y capital
}

\section{Rosa Maria Ruthes', Isabel Cristina Kowal Olm Cunha'}

'Universidade Federal de São Paulo.

Grupo de Estudos e Pesquisa em Administração dos Serviços de Saúde e Gerenciamento de Enfermagem . São Paulo, SP

Submissão: 12/08/2008

Aprovação: 16/10/2009

\section{RESUMO}

Trata-se da revisão sobre prática da gestão do conhecimento e capital intelectual à aplicabilidade das competências para enfermagem. Globalização e competitividade levam as organizações de saúde a buscarem formas de adaptação às transformações da gestão. Cabe ao gestor enfermeiro propor soluções à equipe de enfermagem Quanto aos problemas das organizações de saúde. A gestão do capital intelectual deve cuidar que o pessoal esteja aplicando o saber em benefício da organização e do crescimento profissional. Se não houver competências necessárias para aplicação generalizada de conhecimentos, de nada vale o saber. Os enfermeiros deverão estar preparados para avaliar recursos tecnológicos, organizacionais e humanos e desenvolver competências, conhecimentos, habilidades, atitudes e valores para planejar, organizar, dirigir, controlar o conhecimento nas organizações.

Descritores: Administração de recursos humanos em saúde; Competência profissional; Equipe de enfermagem.

\section{ABSTRACT}

The article presents a review of nurse's management competencies and the practical management of knowledge and the human capital and the applicability of the management for competencies. Globalization and competitiveness makes health organizations to search adaptative forms to the transformations of the management. For the nurse it is expected to consider solutions nursing team related to health organizations problems. The management of the intellectual capital must take care that the personnel is applying the knowing in benefit of the organization and the professional growth. If it will not have necessary competences for generalized application of knowledge, this is useless. The nurses must be prepared to evaluate technological, organizational and human resources and to develop competencies, knowledge, abilities, attitudes, and values to plan, to organize, to direct, to control the knowledge in the organizations.

Descriptors: Health personnel management; Professional competence; Nursing, team.

\section{RESUMEN}

El artículo presenta una revisión de las competencias gerenciales del enfermero y la gerencia práctica del conocimiento y el capital humano y la aplicabilidad de la gerencia para las capacidades. La globalización y la competitividad llevan las organizaciones de salud las formas de la búsqueda de adaptación a las transformaciones de la gerencia. Cabe a la enfermera de manejo considerar soluciones al equipo de cuidado sobre los problemas de las organizaciones de salud. La gerencia del capital intelectual debe tomar el cuidado Que el personal está aplicando el saber en la ventaja de la organización y del crecimiento profesional. Si no tiene capacidades necesarias para el uso generalizado del conocimiento, esto es inútil. Las enfermeras tendrán que ser preparadas para evaluar recursos tecnológicos, de organización y humanos y para desarrollar las competencias - conocimiento, capacidades, actitudes, valores - para planear, organizar, dirigir, controlar el conocimiento en las organizaciones.

Descriptors: Administración del personal en salud; Competencia profesional; Grupo de enfermería. 


\section{INTRODUÇÃO}

A gestão do conhecimento e capital humano é considerada um conjunto de conhecimentos, treino e capacidades das pessoas, Que lhes permite realizar trabalhos úteis, com diferentes graus de complexidade e especialização. Nas instituições de saúde, a gestão não difere nas demais organizações. Pode-se dizer Que é o objeto de uma nova ciência Que está surgindo, baseada em princípios de sistemas, visando à obtenção de fatos certos no foco e no valor ${ }^{(1,2)}$.

No sistema da gestão organizacional, os tomadores de decisão não mais precisam adivinhar ou copiar o Que os outros fazem, pois, com esta nova ciência, eles saberão Quais práticas exclusivamente se encaixam na organização ${ }^{(2)}$.

Lidar com pessoas é função Que demanda uma sensibilidade constante e a complexidade do assunto exige um contínuo aperfeiçoamento técnico. Muitos consideram as pessoas como recursos, alguns estudiosos preferem considerá-las como talentos. Talentos humanos são o Que temos para ser desenvolvido, aproveitado e incentivado nas organizações. Mas a sociedade os denomina humanos e, assim, temos de seguir pensando em pessoas como capital ou, em outras palavras, como recursos humanos ${ }^{(2)}$.

Sabe-se Que só o ser humano, sem o patrimônio, não constitui uma organização, assim como o patrimônio sem esse elemento humano também não constitui uma organização. Fica claro Que uma instituição, seja ela do ramo que for, é um conjunto de pessoas e patrimônio. A pessoa é Que dá a vida, é que dá movimento ao patrimônio: é o principal elemento numa sociedade ${ }^{(2)}$.

Cada vez mais os fatores humanos são considerados como ineeuívocas forças agentes transformadoras e agregáveis ${ }^{(3)}$.

Diante do exposto, este estudo objetivou refletir sobre as competências gerenciais do enfermeiro na gestão do conhecimento e capital humano nas organizações de saúde.

\section{METODOLOGIA}

Para efetivação do objetivo proposto, foi realizada uma extensiva pesquisa bibliográfica em livros, artigos de periódicos e material disponível na Internet ${ }^{(4)}$ isto é, material acessível ao público em geral, Que fornece instrumental analítico para Qualquer outro tipo de pesquisa ${ }^{(5)}$.

A busca foi feita utilizando-se as palavras-chave: "gestão do conhecimento", administração de recursos humanos em saúde”, "competência profissional" e "capital humano" nos bancos de dados DEDALUS, SciELO, Biblioteca Cochrane Plus, BDENF “, equipe de enfermagem e sites relacionados ao tema, nos meses de agosto e setembro de 2007 . Não foi delimitado o período da busca, mas sim, a pertinência de seus conteúdos com o tema proposto.

\section{RESULTADOS}

Os resultados permitiram apresentar os comentários em três grandes enfouues a seguir: conceituação histórica da evolução do capital humano, competências gerenciais do enfermeiro - um desafio na atualidade, gestão por competência uma estratégia diferenciada.

\section{Conceituação histórica da evolução do capital humano}

A Teoria do Capital Humano é uma derivação da teoria econômica neoclássica e, ao mesmo tempo, uma atualização do axioma liberal do indivíduo livre, soberano e racional. Seu prestígio é cíclico. Com a crise do modelo taylorista-fordista, ela ressurgiu associada à redefinição das relações de trabalho na organização e ao papel do sistema educacional.

O termo "Capital Humano" apareceu pela primeira vez nos anos 60, nos EUA. Foi definido como investimento em capital humano - "as atividades que influenciam os resultados obtidos no futuro"(6).

Refere-se Que, o ser humano, por meio da sua formação pessoal e profissional, contribui para o aumento da produção e para o aparecimento de novos serviços. Outros assim explicam Que capital humano é um conjunto de conhecimentos, treino e capacidade das pessoas, Que lhes permitem realizar trabalhos úteis com diferentes graus de complexidade e especialização.

Em função de mudanças no gerenciamento do trabalho, a Teoria do Capital Humano alcançou, nestes últimos dez anos, grande prestígio. Ela se relaciona às práticas e aos debates Que dizem respeito à segmentação do mercado de trabalho, à politecnia, à polivalência, flexibilização e Qualidade total. Situa-se também, no campo de discussão sobre o neoliberalismo em educação ${ }^{(7)}$ e sobre o papel da formação dos trabalhadores como elemento emancipador ou condicionador da ação.

A valorização do capital humano significa a apropriação de Qualidades sociopsicológicas do trabalhador, buscando o consenso e o espírito de lealdade à organização, acenando com a possibilidade de participação autônoma e livre no processo produtivo.

As instituições de saúde também estão reconhecendo que o último recurso da vantagem competitiva e duradoura está para ser descoberto em algo inerente e exclusivo a cada organização: seu capital humano - sua força de trabalho - e os processos para gerenciá-lo.

Assim, para elaborar a melhor estratégia de capital humano é preciso considerar três fatores:

- Sistemas: compreender como várias práticas e programas de capital humano (remuneração, treinamento, gestão de carreiras e supervisão) trabalham em conjunto para produzir os retornos esperados.

- Os fatos certos: contabilidade precisa e detalhada dos atributos da força de trabalho, como das práticas de capital humano tão logo elas sejam realmente implementadas.

- Foco no valor: um foco inflexível no modo como o capital humano impulsiona importantes resultados de negócio - faturamento, lucros, retenção do cliente e Qualidade.

As organizações Que enxergam e começam a agir cedo na identificação na medição dos fatores importantes de capital humano, bem como no ajuste fino da sua estratégia, podem delinear vantagens competitivas significativas e duradouras - às vezes, até em Questão de meses. Os competidores não podem copiar os movimentos de uma determinada organização e obter os mesmos efeitos, porQue não dispõem do mesmo conjunto exclusivo de práticas, políticas e pessoas Que compõem o seu trabalho estratégico $^{(7) .}$

Por outro lado, enQuanto as organizações são julgadas por sua performance, os indivíduos Que as compõem são avaliados por suas competências. Tem-se visto, no Brasil, apoio governamental para formação de pessoas, notadamente para níveis operacionais, uma vez Que a baixa escolaridade tem sido um dificultador para 
recolocação no mercado de trabalho.

Nas últimas décadas, o setor de saúde foi um dos Que apresentou maior taxa de crescimento na oferta de trabalho, chegando a aumentar em torno de $81 \%$ as novas oportunidades de ocupações no período acumulado de 1996 a 2006. O segmento da saúde deverá gerar cada vez mais empregos, porém a posição Que cada indivíduo ocupará vai depender, cada vez mais, do conhecimento Que ele tiver construído ao longo de toda a sua vida ${ }^{(8)}$.

No Que tange à área de enfermagem, são muitos os desafios do cotidiano Que têm influenciado o capital humano. Tais influências geram a falta de clarificação das interfaces entre as políticas públicas e as organizações de saúde, dificultando muitas vezes a prática e a ação. E tudo isto influencia visivelmente, também, o desempenho dos profissionais de saúde. Sabe-se que o reflexo da política sócioeconômica afeta o capital humano, podendo muitas vezes trazer conseQüências sérias às instituições e aos seus usuários, uma vez Que freqüentemente são os profissionais Que vitalizam as organizações. As organizações de alta performance, além de manterem pessoas com alta taxa de empregabilidade, visam também construir e manter equipes sinérgicas e competentes.

\section{Competências gerenciais do enfermeiro - um desafio na atualidade}

As competências Gerenciais do Enfermeiro tornam-se cada vez mais um grande desafio. Fazem-se necessárias para as organizações de saúde, porquanto sendo elas responsáveis pelo cuidado e por toda assistência à pessoa humana, não podem omitir-se e nem deixar de acompanhar o crescimento e investimento do capital humano $^{(9)}$.

Em relação às características Que definem as competências gerenciais de uma equipe de alta performance nos serviços de enfermagem, podem ser citadas: liderança, alinhamento de propósitos, comunicação afetiva, visão comum do futuro, foco no cliente, talentos criativos, rapidez de respostas, responsabilidades e competências compartilhadas, senso de justiça, ética e outras. Todas as características apontadas são comuns a QualQuer organização, independentemente de sua filosofia, estrutura ou estratégia organizacional .

Vale lembrar Que o enfermeiro também é um líder da gestão de pessoas na medida em Que, direta e continuamente, interage com a equipe de trabalho. Sendo assim, não só o gestor de enfermagem, mas cada enfermeiro, como líder, também é responsável pela administração do capital humano. Entretanto, habilidades de liderança e administração são necessárias à mudança de gestão, independentemente da área de atuação ${ }^{(10)}$. É preciso liderar a equipe, recrutar, ensinar o pessoal de enfermagem, não esQuecendo de sempre comunicar e orientar o curso das ações e a prática da assistência, tendo em vista sempre o cuidado como o núcleo da competência $^{(1))}$

Neste contexto, a implementação de novos modelos de ferramentas gerenciais poderá contribuir para o trabalho da enfermagem, não apenas na busca de inovações e construção de organizações mais ágeis e lucrativas, mas também e principalmente na construção de uma assistência humana, visando sempre ao "cuidado com o núcleo de competência, tendo em vista neste aspecto a criação de uma nova práxis". Pode-se dizer Que, assim como a célula sem o núcleo não se desenvolve, também a enfermagem sem "o cuidado", não poderá desenvolver-se como competência. Outras práticas administrativas já estão sendo muitas vezes, incorporadas por outros profissionais; no entanto, a enfermagem deverá lutar para desenvolver todas as competências inerentes ao cuidado do paciente e seus familiares ${ }^{(10)}$.

Nesse âmbito, vive-se numa sociedade espantosamente dinâmica, instável, desafiadora e, ao mesmo tempo, evolutiva. O enfermeiro Que decidir permanecer esperando para ver o Que acontece, corre o sério risco de ficar obsoleto e perder o campo de ação: seu espaço será ocupado por um profissional mais ágil e abrangente nas competências profissionais e organizacionais. ConseQuentemente, entende-se Que a adaptação à realidade atual será cada vez mais uma Questão de desafios à sobrevivência.

Hoje, os sistemas de informações disponíveis nos oferecem uma infinidade de ferramentas: cabe ao enfermeiro saber filtrá-las, extraindo delas o que há de melhor e o Que interessa para as tomadas de decisão Quanto à melhoria das organizações de saúde e de ensino, Qual seja sua área de atuação. Isto significa Que o enfermeiro deverá ser capaz de transferir seus conhecimentos para a prática diária, desenvolver seu julgamento clínico, avaliar o resultado de suas ações, assim como assumir a responsabilidade dos resultados do planejamento da assistência ${ }^{(12)}$.

A Organização Mundial de Saúde escolheu 2006 como o ano dos Recursos Humanos em Saúde, designando sob esta denominação, aQuele grupo populacional Que cumpre um dos mais importantes papéis sociais e humanitários, com grande relevância sócio-econômica, e Que agrega só no Brasil, cerca de 2,5 milhões de profissionais ${ }^{(13)}$.

Nesse contexto observa-se Que os colaboradores insatisfeitos com o trabalho e Que não procuram desenvolver seus conhecimentos, habilidades e atitudes - CHA, estão fadados a ficar fora do mercado. Por outro lado, a definição das políticas de capacitação e a escolha dos profissionais adecuados, bem como os programas Que possibilitam a retenção de talentos, garantem o sucesso (ou não) da instituição de Saúde ${ }^{(14) \text {. }}$

Entende-se Que para alcançar o sucesso é necessário Que os gestores do Capital humano se utilizem das ferramentas de gestão de competências a fim de gerir adequadamente as pessoas. O gestor do capital humano precisa saber, ainda, conduzir as pessoas a realizarem o seu potencial. Isso significa saber gerir os recursos humanos com inteligência, sensibilidade e flexibilidade, o Que requer a atribuição de maior liberdade e responsabilidade na gestão das pessoas.

Um dos desafios na área é Que, para agregar vantagens competitivas, as organizações precisam cada vez mais do envolvimento dos profissionais, oferecendo maiores oportunidades de crescimento e desenvolvimento em troca de comprometimento com os objetivos estabelecidos pela organização ${ }^{(15)}$. Ter um planejamento claro das possibilidades de ascensão dentro da organização é um dos fatores de atratividade dos colaboradores.

A área da Saúde abrange serviços e provavelmente é uma das maiores empregadoras de mão-de-obra especializada, cujo trabalho é produto de inter-relações complexas de vários profissionais atuantes nas mais diversas áreas. Tem como principais objetivos: a prevenção, o tratamento, o restabelecimento, a reeducação e a manutenção da Qualidade de vida dos indivíduos ${ }^{(16)}$.

Para se obter êxito no resultado dos serviços prestados, há necessidade da busca por uma diferenciação( ${ }^{(16)} \mathrm{e}$, neste sentido, 
todo profissional necessita renovar-se continuamente, manter o olhar crítico e investigador e a inquietude a respeito de diferentes aprendizados. Deve investir no desenvolvimento de competências essenciais e duráveis, traduzidas pela associação de conhecimentos, habilidades e atitudes ${ }^{(17)}$.

\section{Gestão por competência uma estratégia diferenciada}

O enfoque nas competências proporciona uma visão mais clara da ascensão, na medida em Que especifica Qual o conjunto de competências para diferentes níveis de carreira do mesmo eixo, ou mesmo de eixos distintos, prestigiando mais o saber fazer, o que o colaborador pode agregar à organização, do Que as tradicionais curvas de maturidade ou níveis de formação técnica ou acadêmica.

A gestão por competências vai muito além da definição de especificações de capacidades para ocupação de um cargo, função clássica de cargos e salários. Envolve estratégias diferenciadas para captação e atração de pessoas, estipula remuneração de acordo com o conjunto de competências e discute, dentro de um conceito próximo à filosofia da Qualidade total, Acreditação, a noção de agregação de valores para a organização.

$\mathrm{Na}$ área de remuneração, pode-se observar com clareza as mudanças decorrentes da gestão por competências. Os sistemas tradicionais de remuneração, Que se baseiam em descrições de atividades e responsabilidades de cada função, têm se tornado anacrônicos em relação à nova organização do trabalho e ao direcionamento estratégico da organização. Nas teorias weberianas, a de remuneração não se alinha à noção de valorização do 'saber agir'. No enfoQue da remuneração estratégica adotam-se novas maneiras de reconhecimento das competências, Que agem como impulsionador de processos de melhoria, convertendo-se, pois, numa vantagem estratégica ${ }^{(18)}$.

Por meio da gestão das competências, é possível, portanto, medir tanto as dimensões físicas Quanto as subjetivas, bem como tornar os comportamentos previsíveis e calculáveis. As pessoas são classificadas e distribuídas no espaço organizacional por meio do desenvolvimento de bases para comparações, Que são as classificações numéricas Quanto ao nível de conhecimento e às Quantidades e tipos de competências. Ou seja, as pessoas são colocadas umas em relação às outras, estabelecendo-se relações de igualdade e diferença, de inclusão e de exclusão ${ }^{(19)}$.

Se uma organização compete com estratégia de excelência operacional, sua competência essencial está nas operações; Quando compete por inovação em produto, a competência essencial vincula- se a pesquisa e desenvolvimento; se compete por orientação para serviços, a competência essencial é o marketing. Assim, pode-se verificar Que competência gerencial é um assunto complexo, Que exige muitas reflexões e pesQuisas, antes de se optar pela sua adoção na gestão de pessoas, principalmente no caso da enfermagem.

Assim sendo, a profissão de enfermagem exige talento, conhecimentos multidisciplinares, atitudes confiáveis, maduras, otimistas e habilidades para agir não só tecnicamente, mas também, e principalmente, com uma entrega humanizadora.

\section{CONSIDERAÇÕES FINAIS}

O estudo levou-nos a inferir Que na era do capital humano, competir nas organizações exige muito trabalho, esforço e determinação e, ao longo da história, os enfermeiros já demonstraram o perfil para responder às exigências impostas pelo mercado de trabalho de saúde, uma vez Que a própria formação do enfermeiro abrange o conhecimento técnico-assistencial acompanhado da prática gerencial.

E como resultado dessa revisão da literatura, verificou-se Que efetivamente, o maior percentual do capital humano de uma organização de saúde é responsável pela prática assistencial e gerencial de enfermagem, uma vez Que o cuidado é o núcleo da competência e parte constituinte da equipe ${ }^{(1)}$.

Os Enfermeiros deverão estar preparados para avaliar os recursos tecnológicos, organizacionais e humanos exigidos para a criação e a gestão do conhecimento, como também desenvolver competências - conhecimentos, habilidades, atitudes e valores - para planejar, organizar, dirigir e controlar a gestão do conhecimento nas organizações de seu capital humano.

Dessa forma, o grande problema para hospitais e outras organizações de saúde Que não se dão ao trabalho de implementar as ferramentas de recursos humanos por competências, é Que eles pagarão, num futuro bem próximo, o preço de não terem feito a escolha mais inteligente: "Investir em Pessoas", ou seja, no seu maior capital ${ }^{(14)}$.

Assim, considera-se Que trabalhar com as competências gerenciais do Enfermeiro é saber buscar evidências e saber exatamente como encontrá-las, usando-as para basear a comunicação em conceitos explícitos e justos, Que tornam objetivos as expectativas, os feedbacks nas avaliações de desempenho e os planos de desenvolvimento individuais do seu capital humano à gestão do conhecimento.

\section{REFERÊNCIAS}

1. Ruthes RM. Gestão de pessoal de enfermagem baseado em competências: uma proposta para as Santas Casas [tese]. São Paulo: Escola de Enfermagem, Universidade Federal de São Paulo; 2007.

2. Mercer Human Resource Consulting LLC e Mercer Investment ConsultinG. [cited 2007 jan 12]. Available from: http:// www.mercerhr.com.br/summary.jhtml?idContent = I I 16885

3. Gentili P, organizador. Pedagogia da exclusão: crítica ao neoliberalismo em educação. Petrópolis: Vozes; 1995.

4. Gil AC. Como elaborar projetos de pesQuisa. São Paulo: Atlas; 1991.

5. Vergara SC. Projetos e relatórios de pesQuisa em administração. São Paulo: Atlas; 2004.

6. D'Innocenzo FLB, Fazenda NRR, Helito RAB, Ruthes RM. Indicadores, auditorias, certificações: ferramentas de qualidade para gestão em saúde. São Paulo: Martinari; 2006.

7. Del Rio EC. Competitividad en tiempo de crisis. [cited 2007 jan 12]. Available from: http:// www.tablero-decomando.com,

8. Terra ICC. Gestão do conhecimento. São Paulo: Negócio Editora; 2000

9. López SP. Elementos claves en la gestión de conocimiento. Un estudio de casos. [cited 2007 jan 12]. Available from: http:// 
www.gestiondelconocimiento.com

10. Ruthes RM, Cunha ICKO. Entendendo as competências para aplicação de enfermagem. Rev Bras Enferm 2008: 6I(I): 109-12.

11. Ruthes RM, Cunha ICKO. Gestão por competência nas instituições de saúde: uma aplicação prática. São Paulo: Martinari; 2008.

12. Cianciarullo TI, organizadora. Instrumentos básicos para o cuidar: um desafío para a Qualidade de assistência. São Paulo: Editora Atheneu; 2000.

13. Cianciarullo IT, organizadora. Instrumentos básicos para o cuidar: um desafio para a Qualidade da assistência. São Paulo: Editora Atheneu; 2000.

14. Fabrizio R. Tendências mundiais em gestão de pessoas. Rev Hospitais Brasil. Disponível em: http www.revistahospitais brasil.com.br/

15. Dutra IS. Profissionais de recursos humanos - um grupo à procura de legitimação [dissertação]. São Paulo: Escola de Administração de Empresas de São Paulo, Fundação Getúlio Vargas; 1987.

16. Marx LC. Competências da enfermagem: sedimentadas no sistema primary nursing. Petrópolis: EPUB; 2006.

17. Ruthes RM, Cunha ICKO, Contribuições para o conhecimento em gerenciamento de enfermagem sobre gestão por competência. Rev Gaúcha Enferm 2007; 28(4): 570-5.

18. Picarelli Filho V. Remuneração por habilidades e competência. São Paulo: Atlas; 1997

19. Townley B. Conhecimento e poder nas organizações. In: Davel E, Vergara SC, organizadores. Gestão com pessoas e subjetividade. São Paulo: Atlas; 2001. p. 117- 43. 